Journal of English Language Teaching and Applied Linguistics

ISSN: 2707-756X

DOI: $10.32996 /$ jeltal

Journal Hompage: www.al-kindipublisher.com/index.php/jeltal

\title{
Co-constructing Writing Rubrics to Enhance Students' Autonomy and Collaboration
}

May Abdul Ghaffar

Head of English language Department, Lycee National Schools, Lebanon

Corresponding Author: May Abdul Ghaffar, E-mail: mayoushkdb@gmail.com

ARTICLE INFORMATION ABSTRACT

Received: November 18, 2020

Accepted: December 14, 2020

Volume: 2

Issue: 5

DOI: $10.32996 /$ jeltal.2020.2.5.5

\section{KEYWORDS}

Co-constructed Rubrics, L2

Learners, Autonomy, Collaboration, Ownership
Many L2 learners show low motivation when it comes to writing. The intervention of this study focuses on the idea of engaging $L 2$ students and their teacher in coconstructing writing rubrics to help them develop a better understanding and awareness of the writing criteria in order to enhance autonomy and collaboration and gain ownership and responsibility for developing their writing skills. This study aimed to investigate the impact of co-constructed rubrics on L2 learners' writing skills and their perceptions towards writing; it also examined to what extent coconstructed rubrics can be used as a learning and assessment tool to help teachers generate feedback conducive to learning and competency development in writing.This mixed methods study integrates both quantitative and qualitative data collection tools and analysis, including pre and post writing assessments for intervention and comparison groups, classroom observations, pre and post interviews with the teacher and L2 students, and a pre and post questionnaire. Results revealed that the intervention class's mean average increased significantly in the post writing assessment, while the comparison class's mean average decreased but with no statistical significance. Moreover, the survey showed that co-constructing the rubrics with the intervention students enhanced their attitudes towards writing. Class observations noted positive changes in the class dynamics and an improvement in the levels of students' interaction and engagement. Coconstructing rubrics has emphasized the fact that writing is a skill that can be taught effectively and can be a solution for those who claim that 'writing is a universal problem'.

\section{Introduction}

From my personal experience in teaching Lebanese L2 learners of different ages ranging from 9 to 17 , I have witnessed students' struggling when it comes to writing. They face difficulties due to different reasons, such as lack of motivation, limited store of vocabulary words, poor sentence structure, and troubles with transferability from L1 to L2, among other reasons. Most students do not see writing as a venue of meaningful expression or ways to critically analyze their thoughts and build their arguments. On the contrary, they perceive it as a challenging chore they want to finish with regardless of the result or the quality of work. A very important question rises here:

How do we equip our students with the knowledge and skills needed to prime them to write eloquently?

I, as a teacher, felt the urgency not only to sharpen my students' writing skills but also to enhance their perception towards writing. It is essential for students to understand that writing grants them a voice, not only to express themselves but also to question curricula as well as society, and enables them to feel free, active, and more engaged. Transforming students so that they see themselves as catalysts of change is highly required and needed in any education system. A second question arises:

How should we, as English Language teachers, teach writing to make it more meaningful for our L2 students and to reach as many students as possible?

K C AL-KINDI CENTER $\mathbf{R}$ D FOR RESEARCH AN Your gatewoy to world-class reecerch
Published by Al-KindiCenter for Research and Development. Copyright (c) the author(s). This is an open access article under CC BY license (https://creativecommons.org/licenses/by/4.0/) 
Writing clearly and eloquently is a skill necessary for our students to meet the demands of universities and the workplace, to provide them with better opportunities to get better positions, and to enable them to play outstanding roles in their societies, for their writing skills can sometimes determine their success or failure. Due to several years of experience and adoption of a hap-hazard, old-fashioned, and outdated curriculum, a very important realization influenced my thinking:

New methods and strategies need to be implemented in order to engage L2 students and motivate them to become young adults who can express themselves rationally and critically. But, how?

If writing rubrics were used to teach the writing process, would their usage enhance students' writing skills? If these rubrics were co-constructed with the learners, would they be used as a learning and assessment tool? Once co-constructed with the students, would they change their perception towards writing?

All of these speculations have arisen from my personal observations where many teachers keep the assessment criteria of writing, a formative assessment tool that students can learn from, to themselves. Working with other teachers, attending various workshops, and taking several MA education courses motivated me to rebel against our outdated and traditional system that is more teacher-centered, where the teacher is the sole source of information and knowledge that is passively received by the students. Hence, I decided to try a new intervention where students collaboratively co-construct the writing rubrics with their teacher to develop better understanding and awareness of the writing criteria and enhance their attitude towards writing and their writing skills.

\section{Co-constructing the Rubrics as an Artefact}

I conducted workshop session with my students to explain to them what rubrics are and what purpose they serve in order to prepare them for generating the rubrics. I gave them a brief introduction of what a rubric is and why it is used. During the session, I did two activities with them to help them understand the meaning and purpose of using rubrics. First, they did a clapping contest where 3 judges evaluated the clapping of three contestants based on Tempo/Frequency, then Volume, and at last Creativity/Enthusiasm to understand the criteria used in the rubrics. Second, I shared with the students' brownies which I had baked a day before and asked them to grade the brownies based on texture, taste, and presentation. These two activities prepared my students for constructing the rubrics.

Next, the students and I worked on constructing the rubrics. As a first step, I divided the class into seven heterogeneous groups of four students each. I distributed a sheet, with a table drawn on it, for each group and asked them to think together of the criteria that their writing samples should be evaluated on. After all of the groups filled their tables with the criteria they came up with, I hung all the sheets on the bulletin board and asked the students to check the sheets of the other groups to compare the criteria that they came up with to the criteria the other groups came up with. Next, the whole class and I were involved in a discussion to unify the criteria that their rubrics will include. The class came up with the following criteria:

- $\quad$ Content/Ideas (Development of Ideas)

- $\quad$ Structure \& Mechanics (Sentence structure; spelling; punctuation)

- Organization (Order of ideas within and across paragraphs/ using transitional devices)

- $\quad$ Style/Creativity (Choice of words; tone; voice)

- Handwriting (legible handwriting + neat paper)

At the end of the session, I asked the students to look up analytical writing rubrics to be able to fill the boxes with the description of each criterion. On the following day, the students and I discussed and negotiated the description and the weight of the grade of each criterion until they reached a mutual consensus. During this session, I made sure that the students understood the description of each criterion. It was clear for the students that their writings will be evaluated based on the rubrics they have co-constructed. It is important to point out that although students came up with the same general criteria that most writing rubrics already include, what is more important is that students could be aware of and understand the meaning of each of the criteria used in the process of evaluation.

3. The Modification of the Assessment process based on the Intervention (Including the Feedback Session)

As regularly adopted in the school, I gave the students the writing topic related to the theme of the unit and asked them to write their essays. Then, I collected the papers and graded them based on the co-constructed rubrics. The grades the 
students received were their initial grade of draft one, which is considered as formative assessment. Based on students' work, I designed an interactive formative feedback session based on their performance on the formative assessment. The feedback session was divided into two parts: self-evaluation and discussion of common problems related to both content and organization and structure and mechanics. First, three volunteers self-evaluated their work, discussing how fair their grades were, their strengths and challenges, and how to improve their performance based on the co-constructed rubrics. Later, the students and I discussed students' common mistakes based on the co-constructed rubrics, regarding content and structure, and engaged the students in the correction of these mistakes. The students and I identified the common problems, and I asked them to check their papers to think of ways to correct these mistakes. The purpose behind this feedback session was to build a trusting environment with the students in which they become engaged in the assessment process. This, also, shows students that writing is a process and there is always a room for improvement. After the feedback session, I asked the students to write the second draft in class in order to give them a chance to improve their writings and benefit from the feedback session which was generated based on the co-constructed rubrics. I collected the second draft and graded it based on the co-constructed rubrics, which is the summative assessment on which they will receive their final grade. Their total grade would be calculated based on the following percentages: $50 \%$ for the formative assessment and $50 \%$ for the summative assessments. This writing process ensures that the small gains they earn every time they pass through this process would lead to larger gains on the long run.

\section{Students' Demands for Fundamental Changes in the Writing Process}

When the intervention was planned, including a feedback session of self-evaluation and discussion of common mistakes, it was essential to maintain the integrity of the notion of co-constructed rubrics as a learning and assessment tool. The coconstructed rubrics, serving as means of formative assessment for further learning, built a trusting environment with the students and encouraged them to become engaged in the assessment process, enhancing collaborative and autonomous learning. Students wrote the first draft as formative assessment, discussed their mistakes during the interactive feedback lesson to be able to edit their pieces of writing, and then wrote the final draft as summative assessment. The phase of brainstorming ideas before asking the students to write the first draft, as another form of formative assessment, was not included. Thus, before applying the same process for the second writing task, students demanded that they brainstorm ideas in order to build enough background information about the topic. Accordingly, a complete writing process in the intervention class, with all of its different phases: brainstorming, formative assessment, interactive feedback lesson, and summative assessment, was adopted. This whole process gave the students different chances to improve the quality of their work. After they wrote the first draft based on brainstorming, they were given the chance to self-evaluate their work. Then, they were engaged in a mini lesson to discuss their mistakes and think of ways to correct these mistakes.

Despite the fact that the process that was developed based on the intervention with in a safe and collaborative climate and classroom tasks - the complete writing process with its four principal phases: Brainstorming (a phase, requested by students), Writing the First Draft as a formative assessment, Editing in the form of an interactive feedback lesson, and Writing the Final Draft as a summative assessment-is actually very similar to the process that is already in widespread use by writing teachers in a variety of contexts, the intervention reflects a positive attitude toward students' writing and toward the teaching strategies adopted to implement this intervention. While some of the steps might already be familiar in other contexts, they were new in the school where the intervention was implemented. What is highly significant about this intervention is that it engaged students in the teaching/learning process and helped them grow as catalysts of change for further improvement.

\section{Positive Influence of Co-constructing Rubrics as an Artefact on Students' performance}

After adopting co-constructed rubrics, students were better aware of the criteria and quite clear about the expectations: They understood how they have been evaluated. This has reflected positively on their perception and attitude towards writing.

Enhanced perceptions towards writing along with the change of the writing process seemed to have a positive impact on students' achievement in writing. Having better attitudes and perceptions affected both the learning climate and the classroom tasks. During the intervention, I dealt with the learning climate when I organized students into cooperative groups and gave them the chance to play a major role in the teaching/learning process. Thus, students perceived the classroom as a safe environment to learn and feel comfortable. It was, also, obvious in the change of the classroom setting. Instead of ordering the desks in rows and columns, as it is usually the case in a traditional class, I had to organize the desks in groups of four to promote cooperation and interaction among students. As for the classroom tasks, the intervention helped students understand and gain clarity over the writing tasks and their goals; consequently, they understood the meaning and value of 
these tasks. The intervention called for fundamental changes in the writing process that has been adopted in the school. The complete writing process with its four principal phases: Brainstorming (a phase, requested by students), Writing the First Draft as a formative assessment, editing in the form of an interactive feedback lesson, and Writing the Final Draft as a summative assessment had to be adopted to serve the purpose and function of the intervention. Attending to these two categories- learning climate and classroom tasks- helped students develop positive attitudes and perceptions about the learning climate and classroom tasks, which was reflected in both their perceptions and performance.

\section{Autonomy in Learning and Class Dynamics}

Another important factor that emerged was enhanced student autonomy in learning, which enhanced class dynamics. Of special interest was the shift in students' and teacher's roles. The whole class changed from being teacher-centered where teacher provides students with knowledge and evaluation remarks received passively to being student-centered where students participate in the teaching/learning and assessment process. Students had the chance to evaluate their work, identify their strengths and weaknesses, and think of ways to improve their work. Students self-evaluated their work, asked the teacher questions, and worked collaboratively to find ways to improve their work. Students reported that the intervention was a positive and beneficial experience because it allowed them to play a role in the assessment process, allowing them to improve their academic performance, gain agency over the teaching/learning process, and promote autonomy and ownership.

\section{Students' Ownership and Self Awareness}

The intervention enhanced students' involvement in the assessment process and reinforced their belief that they can improve their work. This fact increased their ownership over the learning process which reflected positively on the whole teaching, learning, and assessment process. Students no longer felt that the learning and assessment process is something mandatory, rigid, and imposed on them. They had the chance to be involved, change, modify and express their opinions regarding what is going on in class. Changes brought about by the intervention and students' contribution have led them to be more satisfied expressing that their knowledge of criteria enhanced fairness of assessment. Throughout the intervention, students were active participants playing different roles starting with looking for information to construct their rubrics and ending with correcting and self-evaluating their work.

Students' sense of ownership may have been influenced by their perception of enhanced fairness and acknowledgment of their needs. The new distribution of power in the writing classroom enhanced their trust in admitting their weaknesses because they were learning in a safe environment where there was room for improvement. They were less judged for the mistakes they committed and more encouraged to find ways to improve the quality of their work. In turn, their writing performance showed improvement.

\section{Conclusion}

Co-construction and use of writing rubrics were found to impact students positively and enhance their performance in writing. Students' participation in co-constructing and using the writing rubrics had a strong positive influence on students' attitudes and perceptions towards writing. The study of co-constructed writing rubrics showed that the process of coconstructing and discussing the rubrics increased students' interactions in the classroom. This high level of interaction and participation showed students as more active leaners and transformed the classroom into a more student-centered one, where students self-evaluate and collaborate to improve their writing. This study has served as a professional development moment for the teacher and highlighted the fact that students' participation and involvement in the teaching and learning process helps them better comprehend the evaluation and assessment criteria.

During my years of experience, I had the chance to reflect on our schooling systems which are designed to categorize students into either successful or failing students. In doing so, we, as educators, are applying restrictive measures to overlook or obscure the student's potential to learn from his/her mistakes and thus improve. This experience has allowed me to turn my students' frustration into an active plan where they were involved and actively participated in the teaching/learning process. Our role, as educators, is simply not to teach and assess our students' work but to create opportunities for change and further improvement in our teaching strategies allowing students to gain more agency. Better pedagogies have to be adopted to better teach, assess, and evaluate our students' strengths. 


\section{References}

[1] Ahmed, H. (2010). Students' problems with cohesion and coherence in EFL essay writing in Egypt: Different perspectives. Literacy Information and Computer Educational Journal (LICEJ), 1, 211-221.

[2] Al-Gharabally, M. (2015). The writing difficulties faced by L2 learners and how to minimize them. International Journal of English Language and Linguistics Research, 3(5), 42-49.

[3] Andrade, H. G. (2000). Using rubrics to promote thinking and learning. Educational Leadership, 57(5), $13-18$.

[4] Andrade, H. G. (2001). The effects of instructional rubrics on learning to write. Current issues in Education, 4(4), 1- 21.

[5] Andrade, H., \& Boulay, B. (2003). The role of self-assessment in learning to write. The Journal of Educational Research, 97(1), 21-34.

[6] Andrade, H., Du, Y., \& Mycek, K. (2010). Rubric-referenced self-assessment and middle school students' writing. Assessment in Education: Principles, Policy \& Practice, 17(2), 199-214.

[7] Andrade, H., Du, Y., \& Wang, X. (2008). Putting rubrics to the test: The effect of a model, criteria generation: and rubric-referenced self-assessment on elementary school students' writing. Educational Measurement: Issues and Practices, 27(2), 3-13.

[8] Andrade, H., Wang, X., \& Du, Y. and Akawi, R. (2009). Rubric-referenced self-assessment and self-efficacy for writing. The Journal of Educational Research, 102(4), 287-301.

[9] Annous, S. A., Nicolas, M., \& Townsend, M. A. (2017). Territorial borders and the teaching of writing in English: Lessons from research at the University of Balamand.

[10] Bacha, N. N., \& Bahous, R. (2011). Foreign language education in Lebanon: A context of cultural and curricular complexities. Journal of Language Teaching and Research, 2(6), 1320-1328.

[11] Bahous, R., Bacha, N. N., \& Nabhani, M. (2011). Motivating students in the EFL classroom: A case study of perspectives. English Language Teaching, 4(3).

[12] Becker, A. (2016). Student-generated scoring rubrics: Examining their formative value for improving ESL students' writing performance. Assessing Writing, 29, 15-24. doi:10.1016/j.asw.2016.05.002

[13] Bowen, T., \& Marks, J. (1994). Inside teaching: Options for English language teachers. Oxford: Heinemann Publishers.

[14] Brookhart, S. (1999). The art and science of classroom assessment: The missing part of pedagogy. Washington, DC: The George Washington University Press.

[15] Brown, S. (2005). Assessment for learning. Learning and Teaching in Higher Education, 1, 81-89.

[16] Ene, E., \& Kosobucki, V. (2016). Rubrics and corrective feedback in ESL writing: A longitudinal case study of an L2 writer. Assessing Writing, 30, 3-20. doi:10.1016/j.asw.2016.06.003

[17] Fareed, M., Ashraf, A., \& Bilal, M. (2016). ESL learners' writing skills: Problems, factors, and suggestions. Journal of Education and Social Sciences, 4(2), 81-92.

[18] Graham, S. \& Perin, D. (2007). Writing next-effective strategies to improve writing of adolescents in middle and high schools. Journal of Education and Social research, 2(3), 17-27.

[19] Houssami, M. N. (2005). A Comparative study of the effect of student-generated and teacher-provided instructional rubrics on writing achievement (Unpublished master's thesis). American University of Beirut, Beirut, Lebanon.

[20] Hyland, K. (2003). Second language writing. Cambridge: Cambridge University Press.

[21] Khuwaileh, A., Shoumali, A. (2000). Writing errors: A study of the writing ability of Arab learners of academia English and Arabic at university. Language, Culture and Curriculum, 13, 174-183.

[22] Kroll, B. (1990). Second language writing. Cambridge: Cambridge University Press.

[23] Mertler, C. A. (2001). Designing scoring rubrics for your classroom. Practical Assessment, Research and Evaluation, 7(25), 1-10.

[24] Moskal, B. M. (2000). Scoring rubrics: What, when, and how? Practical Assessment, Research, \& Evaluation, 7(3), 1-5. Retrieved from: http://pareonline.net/getvn.asp?v=7\&n=3

[25] Panadero, E., \& Jonsson, A. (2013). The use of scoring rubrics for formative assessment purposes revisited. Educational Research Review, 9, 129-144.

[26] Rezaei, A. R., \& Lovorn, M. (2010). Reliability and validity of rubrics for assessment through writing. Assessing Writing, 15(1), 18-39.

[27] Schirmer, B. R., \&Bailey, J. (2000). Writing assessment rubric: An instructional approach for struggling writers. Teaching Exceptional Children, 33(1), 52-58.

[28] Shaaban, K. A., (2013). Disparity between ideals and reality in curriculum construction: The case of the Lebanese English language curriculum. Creative Education, 4(12), 28-34.

[29] Shehab, M. (2011). Teachers' and students' perspectives on using rubrics in the writing classroom (Unpublished master's thesis). Lebanese Academic University, Beirut, Lebanon.

[30] Shukri, N.A. (2014). Second language writing and culture: Issues and challenges from the Saudi learners' perspective. Arab World English Journal, 5(3), 190-207.

[31] Skillings, M. J., \& Ferrell, R. (2000). Student-generated rubrics: Bringing students into the assessment process. The Reading Teacher, $53(6), 452-455$.

[32] Stergar, C. (2005). Performance tasks, checklists, and rubrics. Glenview, Ill: LessonLab.

[33] Stevens, D. D., \& Levi, A. J. (2005). Introduction to rubrics: An assessment tool to save grading time, convey effective feedback, and promote student learning. Virginia: Stylus Publishing. 